\title{
Changing habitats of the world
}

Martin W. Holdgate

The world is being altered by human action more rapidly now than natural forces changed it during any short period in the past. There are predictions of massive ecological changes and extinctions of species on a unprecedented scale. The author examines what is actually happening, what the consequences are likely to be, and what corrective action can be taken. He emphasizes that, as with all exercises in crystal gazing, this cannot be an error-free analysis. Despite the vast scale of current scientific activity, our knowledge of the processes affecting the world environment and our monitoring of changes are far from adequate. Too many statements - including widely quoted estimates of extinctions-are based on extrapolation from limited data. This is a speculative paper intended as a spur to further analysis rather than as a definitive review. It is based on an address to the Annual General Meeting of the Fauna and Flora Preservation Society on 10 September 1986.*

\section{The natural background of change}

Many scientific reviews have attempted to describe how the earth, as a habitat, has changed over the 4.5 billion years of its history. The principal changes they discuss are in the composition of the atmosphere, the climate, the distribution of continents and oceans, and sea levels. It is generally believed that the earth initially had an atmosphere dominated by carbon dioxide and nitrogen, and lacking free oxygen (Pollack, 1981). The release of oxygen is commonly ascribed to the activity of photosynthetic organisms, the oldest of which were blue-green algae. This change occurred far back in the preCambrian, at least 2 billion, and judging from recent finds of earlier fossil algae perhaps 3 billion years ago. Since then oxygen has been an important component of the air, and for over 1 billion years it has remained steady at about 20 per cent of atmospheric composition.

Global circulation models indicate that the broad patterns of atmospheric layering, with boundary

*The views expressed are those of the author, as an individual ecologist, and not necessarily those of the Department of the Environment.

Changing habitats of the world layer, troposphere and stratosphere, and of circulation, with polar high pressure, temperate depression belts, and tropical high pressure, have also been an enduring feature. Regional phenomena like the monsoons, however, may reflect structural features, like the arrangement of land and sea, dating from relatively recent eras.

The fluxes of carbon through the biosphere are unlikely to have been constant. Much of the carbon dioxide that formerly dominated the earth's atmosphere is now locked up in the rocks (Pollack, 1981). The carbonates in limestones represent the largest single pool of the carbon formerly active in biological systems. Without this 'sink', the earth might well have had a runaway 'greenhouse' atmosphere like Venus, inimical to life. Knowledge of the global carbon cycle has increased recently, illuminating the dynamic equilibrium between carbon dioxide in the atmosphere, photosynthetic uptake and respiratory release, bicarbonate in the sea water, carbonate in the skeletons of marine organisms, and the sirk provided by the rocks (Figure 1). Current analyses suggest that a doubling of atmospheric carbon dioxide from the pre- 
industrial level of about 250 to 500 p.p.m.v. could lead to a global warming of about $3 \pm 1.5^{\circ} \mathrm{C}$. We may speculate that atmospheric concentrations could well have varied in previous epochs in a fashion that must have some effect on climate and on habitats. Pollack (1981) considers that the greenhouse effect of the high carbon dioxide levels in the earth's early atmosphere may have been important in counteracting the lower solar luminosity at that time and maintaining moderate surface temperatures. Other calculations suggest that, were there no greenhouse gases in today's atmosphere, mean temperatures would be some $30^{\circ} \mathrm{C}$ lower than they are. It is obvious that variations in atmospheric composition can therefore be of crucial ecological significance.

The earth has also experienced periodic meteoric impacts. Large craters are visible, despite weathering, in a number of places. Some calculate that an object $10-20 \mathrm{~km}$ across might be expected to strike the earth every 50-100 million years (Shoemaker, 1981). Such a massive impact would cast a dust veil into the stratosphere far greater than that accounted for by even a great volcanic eruption like Krakatoa, and comparable with that created by nuclear war. In the latter connection, recent studies imply that detonation of some thousands of megatons of nuclear devices would cut incident light to about 1 per cent of normal in the northern hemisphere (which is where the conflict is assumed), and surface temperatures could drop to about $-40^{\circ} \mathrm{C}$ in continental interiors (Ehrlich et al., 1983). Photosynthesis would come to a halt for some months over broad areas of the globe. Some writers have postulated that a meteoric impact in the past, causing a similar cutting off of the sunlight and a halt to green plant activity, may have been associated with large-scale extinction of herbivores-and especially large, long-lived forms like the big dinosaurs - favouring at the same time the survival of carrion and debris eaters, and those able to exist on the seeds and fruits from which revegetation proceeded. It has been suggested that such events may account for the five or six major periods of extinction claimed to appear in the fossil record. This is at present no more than hypothesis, but there can be no doubt that such meteoric impacts would have had a considerable ecological effect. On a more modest

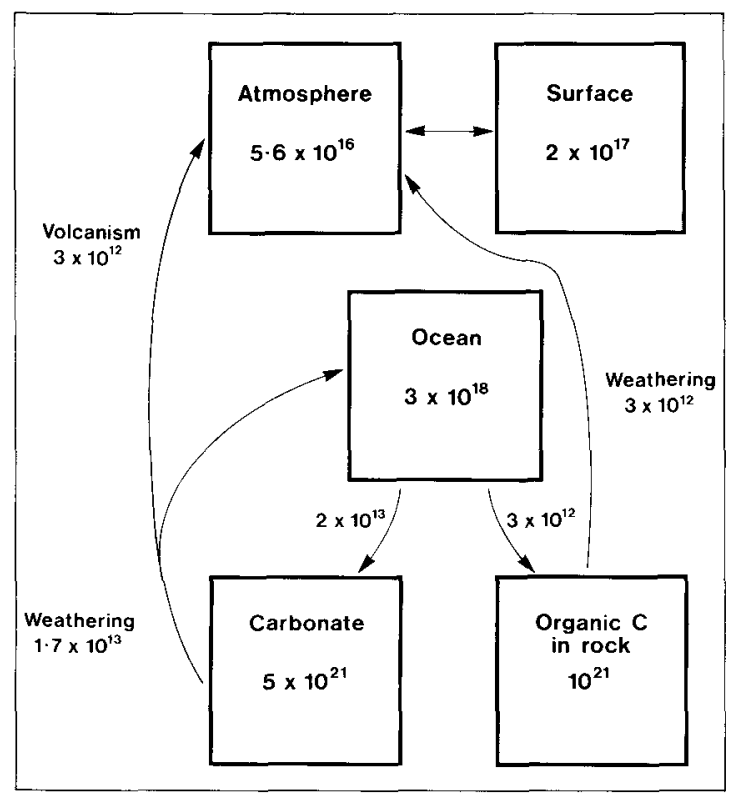

Figure 1. Carbon in the earth's environment. Boxes indicate the totals present in various components at any one time (in moles C) and arrows indicate annual fluxes. The dominance of the rocks as a reservoir is apparent. Source redrawn from Pollack (1981).

scale, fluctuations in volcanic activity may well have been reflected in temperature patterns (Lamb, 1970, 1977).

Finally, we are all familiar with the phenomena of cyclical Pleistocene glaciations. These are now believed to have been determined primarily by regular cyclical variations in the earth's orbit. However, this cannot be the sole factor, for until a few million years ago there had been no ice ages in the Northern Hemisphere for almost 300 million years despite the existence of the same astronomical pattern. It is possible that land distributions have played a crucial role (Pollack, 1981), just as the thermal asymmetry between the hemispheres-which may have been as marked as $20^{\circ} \mathrm{C}$ in mean temperatures at comparable latitudes at some times in the Tertiaryalso reflects the changing arrangements of the continents (Flohn, 1978).

Through recent growth in the understanding of plate tectonics, we have come to recognize how the major land areas of the planet have redistributed themselves over geological epochs. Most important for biologists has been the break up of 
Pangaea, which began over 200 million years ago, the progressive separation of the components of the great southern land mass Gondwanaland from the Jurassic onwards, the subsequent attachments of the two Americas and of India to Asia, and the detachment and movement of Antarctica to a southern polar position, some 35 million years ago (Figure 2). This latter event, giving a hub of land within an oceanic ring in the far south, acted to modify southern hemisphere oceanic and atmospheric circulations and to stabilize southern glaciations (a substantial Antarctic ice cap has been there since the Oligocene, and in its present form for some 10 million years) (Flohn, 1978). In the northern hemisphere, by contrast, the circumpolar land at the margin of permanent glaciation has provided the base for oscillating ice sheets.
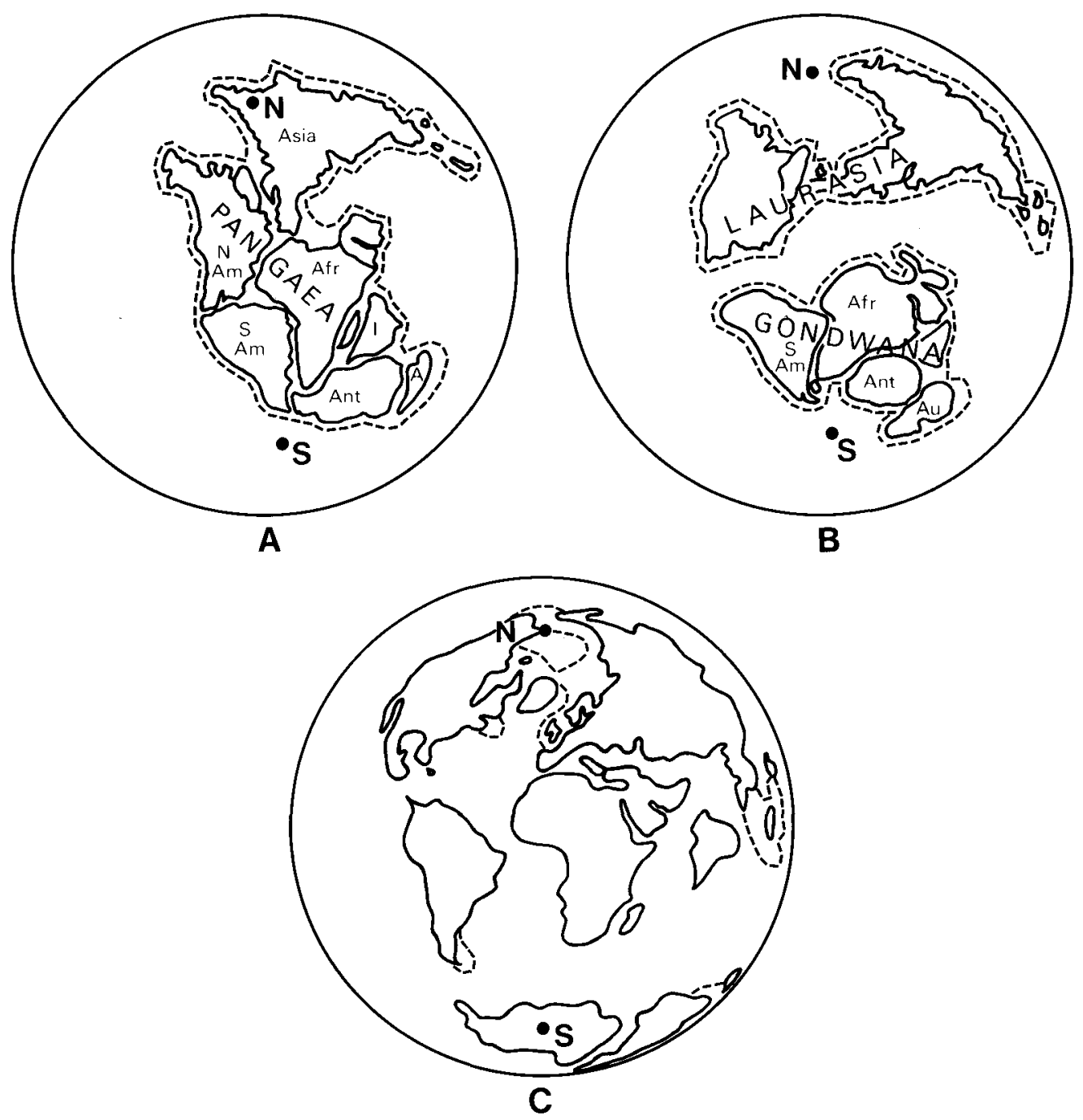

Figure 2. The changing pattern of the continents: A: Pangaea, 250 million years ago; B: Laurasia separated from Gondwanaland, 150 million years ago; $\mathrm{C}$ : Gondwanaland broken up, 50 million years ago. 
Linked with these changes have been those of sea level and oceanic island building. At Pleistocene ice maxima sea level stood about $50 \mathrm{~m}$ below the present: it is calculated that the melting of all today's land ice would raise the sea level by a further $50 \mathrm{~m}$. There is thus approximately $100 \mathrm{~m}$ of oscillatory potential in sea level due to glacial cycles interlocked with land configuration changes. Locally, of course, the elastic depression of the crust by ice loading, and elastic recovery through deglaciation, has caused larger movements.

Oceanic island building is a phenomenon of midocean ridge spreading. Such islands arise as volcanoes on upwelling zones. They are displaced laterally with age as spreading proceeds. Some chains, like Hawaii, are built as a crustal area moves over a deep convective hot spot in the mantle. Old islands tend to subside once volcanic construction ceases, but in tropical seas this can be more than offset by coral growth, providing the familiar atolls with no visible volcanic rock.

What does all this add up to biologically? It is generally assumed that ecological diversity is a reflection of the age, size, structural diversity, climatic quality and climatic stability of a habitat. Areas like Amazonia or Zaire are biologically rich because they have experienced tropical pluvial conditions for many millions of years, allowing the rain forest system to evolve with its multiplicity of niches and interactions. Older oceanic systems like Hawail or the Galápagos, although much poorer than tropical continental areas, are biologically richer than many small remote islands because of their greater age, diversity and extent. In contrast, continental lands that have recently been glaciated, like the Arctic or southernmost South America, have restricted biotas as a result of recent ecological instability and less favourable cool climates with large seasonal variations. Places on the fringes of such areas where rising post-glacial seas have created barriers to biological migration, such as Britain, Ireland, the Falkland Islands or Tierra del Fuego, are expectedly and exceptionally impoverished.

Evolutionary divergence has proceeded behind oceanic and other barriers. South America became separated from the rest of Gondwana152 land, except for the Antarctic Peninsula, about 60 million years ago. It evolved a characteristic mammalian fauna, retaining 15 genera of marsupials and supporting 29 families of placental mammals of which only two also occurred in North America. About 2 million years ago the Americas became reconnected via Panama. The consequent two-way flux of organisms led to progressive unification of the mobile mammalian faunas (although not the tropical forest trees and associated narrow-spectrum invertebrates, presumably because there was, for example, no North American counterpart of Amazonia). However, in the process North American forms did better: all the distinct South American ungulates became extinct. The total number of families of mammal in South America, however, remained the same (at 29) after reunification (Simpson, 1953; Darlington, 1957).

This is the kind of background we need to bear in mind when we seek to evaluate current trends. The world has never gone through a period without change, evolution and extinction. What we are now seeing is the addition of human perturbations, with consequences for the distribution, evolution and extinction of species.

\section{Current changes in the world environment}

There is every reason to believe that the natural processes outlined above are continuing. The North Atlantic sea floor is spreading and the ocean widening at a rate of over a centimetre a year. Other oceanic spreading zones are behaving in a similar way. Oceanic islands continue to appear and grow. Volcanicity shows unpredictable variation, and it may be assumed that there will be further meteoric impacts. The cycles of glaciation and retreat are expected to continue. However, today we have to take human perturbation of the biosphere into account. In this connection, there are three significant kinds of impact to consider. First, there are the effects of human modifications of atmosphere, climate and aquatic habitats through pollution. Second, there is the role of man as an agent of biological distribution. Third, there is the direct pressure of Homo sapiens as an unprecedentedly dominant species, changing eco-

Oryx Vol 21 No 3, July 1987 
systems so as to secure particular biological and other products useful to mankind.

Any analysis of these impacts has to be done in critical awareness of the limitations of the data. We have been bombarded by sweeping generalizations, some of them self-evidently absurd. For example, over 10 years ago news headlines announced that chemical pollution was causing 'the death of the ocean'. Anybody who has looked at world fishery statistics or the results of ecological surveys since 1970 knows that, while over-exploitation has altered the composition of global fishery catches and jeopardized the survival of several species of great whale, and while chemical and organic pollution has done ecological damage in many estuaries and shallow coastal seas, oceanic ecosystems as a whole do not show major transformation (Holdgate et al., 1982). Similarly, there have been many alarming statements about the likely disappearance of all tropical forests by some forecast date in the next century. Estimates of forest clearance have ranged from 6 to over 20 million hectares a year-largely a reflection of the differences in definition, method of estimation and lack of basic data (Table 1). The best analysis so far, by the United Nations Environment Programme and the Food and Agriculture Organization, suggests that some 7.4 million hectares of tropical forest are being converted to other types of vegetation every year. This is a large total, and disturbing enough, but it requires more critical analysis of what is happening to what land, where, and what kinds of vegetation are being put in its place before we can judge its ecological significance. And it would be misleading to extrapolate forwards and assume that it automatically means the total disappearance of all tropical forests at the date when a straight-line plot cuts the abscissa of the graph.

The more critically that global trends are examined, the worse the science actually looks. The fact is that there are only a few really reliable bodies of monitoring information. We have good records of climate and weather, now greatly extended by satellite information. We have some reliable global measurements of atmospheric carbon dioxide concentrations, and less good information about ozone and sulphur dioxide. Mostly, however, pollutant measurements in air, water and wildlife come from the industrialized countries. We have estimates of land use, fishery and crop yields, and records of human population sizes, living conditions and health statistics. There are data on energy use and industrial activity, again mainly from the developed countries. This year, however, two attempts at data compendia, by the World Resources Institute (1986) and the United Nations Environment Programme (1987), have revealed the inadequacies of the database. Our understanding of the scientific mechanisms underneath the phenomena we observe is weaker still. Only now, for example, is a consensus being reached about

Table 1. Some estimates of forest depletion

\begin{tabular}{|c|c|c|c|}
\hline Date of estimate & Author & Estimate (million ha/year) & Notes \\
\hline 1976 & Sommer & 11 & $\begin{array}{l}\text { 'Tropical moist forest'; data from } 13 \\
\text { countries only }\end{array}$ \\
\hline 1978 & 8th World Forest Congress & 16 & 'All tropical forests' \\
\hline 1979 & Lanly and Clement & 6 & 'All tropical forests' \\
\hline 1980 & Myers & $\begin{array}{l}20 \\
\text { (10 million permanently } \\
\text { converted to cultivation }\end{array}$ & $\begin{array}{l}\text { Data from } 18 \text { countries assumption of } \\
20 \text { million families clearing } 1 \mathrm{ha} / \mathrm{yr}\end{array}$ \\
\hline 1980 & Seller and Crutzen & $20-62$ & $\begin{array}{l}\text { All biomes: only } 0.5-1.5 \text { million ha being } \\
\text { virgin closed forest }\end{array}$ \\
\hline 1980 & $\mathrm{FAO}$ & 7.4 & $\begin{array}{l}\text { Closed forest: in addition } 3.8 \text { million ha/yr } \\
\text { of open woodland cleared and } 4.4 \text { million } \\
\text { ha affected by selective logging }\end{array}$ \\
\hline
\end{tabular}

Sources: Holdgate et al., 1982; Postel 1984. 
the role of 'acid rain' in causing the changes in Scandinavian freshwater ecosystems that have been a matter of concern for decades.

Thus, any global statements are bound to stretch both data and understanding of environmental processes to the limit-or beyond the limits an engineer or physicist or practical citizen would demand as a basis for decisions on which life and money rest. Yet many lives and vast sums of money turn on the right environmental decisions. In the specialist area represented by this Society the success - and credibility - of the conservation movement depends on sound judgement of what will happen to habitats and how species will respond. Ecologists and conservationists need to be especially careful about extrapolations; they should make the basis for their statements explicit, and should press the case for better monitoring and better science! It would be wise to avoid palpably nonsensical statements like one made in a letter to The Times on 2 September 1986 that the time will come when all wildlife is driven from the face of the earth'. Anyone disposed to believe such an assertion should ponder how humanity could survive without the wild organisms in the decomposer cycle, the wild plants that grow in places useless to man and that play an important part in the carbon and oxygen cycles, or the ecosystems of the oceans.

\section{The effects of pollution}

Against this background of uncertainty, what generalizations can we make about the effects of contamination of the biosphere? I suggest that the global trend that is going to have the most profound influence on the world's flora, fauna and, indeed, human life is the continuing accumulation in the atmosphere of the 'greenhouse gases' - carbon dioxide, methane, nitrous oxide and chlorofluorocarbons (Clark, 1982).

There is good evidence to suggest that carbon dioxide concentration in the atmosphere has risen by about 30 per cent since pre-industrial times and is likely to double by around 2070 . There are also good reasons for believing that nitrous oxide, methane and chlorofluorocarbons we use as aerosol propellants, refrigerants and agents in the manufacture of insulating plastic foams can also have a 'greenhouse effect', their 154 combined impact being about equal to that of carbon dioxide. The best 'guesstimate' is that the combined consequence may be a rise in mean world temperature by $3 \pm 1.5^{\circ} \mathrm{C}$ over the preindustrial (1850) 'baseline' by the middle of the next century, and that near the poles the rise could be a good deal more-perhaps up to $8^{\circ} \mathrm{C}$. The uncertainties are over the rate greenhouse gases will be released (we are still not sure where the methane and nitrous oxide come from), the interactions between atmosphere and ocean, and the effect of this warming on cloud and rain distribution and on the ice caps and sea level. The World Climate Programme is trying to resolve these uncertainties.

The best guesses are that temperatures have already risen about $0.5^{\circ} \mathrm{C}$ and that sea level has risen by about $25 \mathrm{~cm}$ over the past century, due largely to thermal expansion of the oceans rather than ice melt, and that by 2070 we may have to cope with sea levels some $50 \mathrm{~cm}$ to $1.5 \mathrm{~m}$ higher than now. The rainfall effects are uncertain, but some models-no better of course than the understanding on which they are based - suggest accentuation of present patterns. In other words, wet areas will get wetter and warmer and dry areas hotter and dryer. One North American study (Environmental Protection Agency, 1984) implies a wetter zone in eastern USA and Canada, little change in the Great Plains, but a drier Colorado.

Such changes would have obvious ecological implications. Many major biomes are more or less zonal, with boundaries that match isotherms and rainfall limits. In the north, for example, the limit of closed coniferous forest more or less coincides with the $10^{\circ} \mathrm{C}$ July isotherm. A $4^{\circ} \mathrm{C}$ warminghalf that shown for the polar regions on some models-would bring the forest to the northern shore of Alaska, the Mackenzie delta, and most of Siberia. The consequent massive reduction in open tundra would have considerable implications for the open-ground nesting Arctic birds, including many migratory wildfowl. If the warming meant substantial reduction in Arctic sea-ice and increased winter snowfall on the other hand, this could cause an advance of the mountain glaciers and ice caps, perhaps further attenuating the open treeless habitats.

Oryx Vol 21 No 3, July 1987 
One can speculate similarly about other zones. In the far south, where unglaciated land in the South Shetland and South Orkney Islands has a mean temperature of only $0-1^{\circ} \mathrm{C}$ in the warmest month and is too harsh for higher plants and macroinvertebrates, a $4^{\circ} \mathrm{C}$ rise would almost certainly allow the development of small areas of southern tundra and a relatively diverse insect fauna. In temperate regions the general poleward shift of the isotherms would obviously be reflected in distribution changes of plant and animal species, but here and in the tropics the adjustment of precipitation patterns would be likely to have the more profound influence. Plant productivity would be expected to increase generally, where water supply was not limiting, stimulated directly by the higher availability of carbon dioxide (this, incidentally, provides one possible control mechanism if more carbon was abstracted to the standing crop of plant matter or to soil humus and peat). Climatic change and human pressures would tend to reinforce one another in many places, for example the Sahel where drought and misuse of the land has brought the deserts marching south at up to $5 \mathrm{~km}$ a year. If the dry plains of the USA - where agriculture is already in trouble and has been over-pumping groundwater to stay in business-became truly arid, we could see considerable adjustments in economic as well as ecological patterns. What happens to the Soviet steppes if they too get drier? Meanwhile, a wetter, warmer western Europe and perhaps parts of India, East Africa and South East Asia could gain in relative agricultural significance, and Amazonia, Zaire or Indonesia, hotter and wetter still, might be less attractive to deforesters and cultivators.

There would be further implications for coastal wetlands in such diverse places as Bangladesh, Florida, the eastern United States and north-west Europe. Many people live, and many important wildlife habitats are found, on land that would either be submerged or need extra protection from a $50 \mathrm{~cm}-1 \mathrm{~m}$ higher sea. In many parts of the world, away from centres of population, there is simply no way of stemming these marine encroachments. Elsewhere sediment accretion and plant and coral growth might keep pace (coral reefs can grow by several millimetres a year and have coped with considerable sea level changes in the past), but faster change could kill reefs and also have a serious impact on mangrove woodlands. In populated areas, engineering works to protect low-lying hinterlands, especially if it became cheaper to straighten up runs of marshy coast and put barrages across shallow estuaries, could have a major impact on, for example, invertebrate and bird habitats in places like western Europe and eastern North America. All in all, rapid sea level change clearly poses substantial problems for flora and fauna in many places (Dahl, 1986).

All this remains speculation, but it at least demonstrates how important it is to establish a sound scientific basis for judgement. The impact on plants and animals will come far more through the shift of moisture belts and the consequent readjustments of human communities than through the direct impact of temperature change, which will be within the tolerance of virtually all species even though their zones of distribution will adjust. Given the tenacity of people, communities are likely to cling to established land-use patterns longer than ecological wisdom would suggest. Better predictive skills will allow pre-adaptation through planning and training, thus sustaining livelihood by adjustment to the changing ecological context.

The 'greenhouse effect' is almost certainly the biggest global change likely to be brought about by human perturbation of the atmosphere. At regional level the effects of 'acid rain' are the most publicized and significant (McCormick, 1985; Royal Society, 1984). Since the 1940 s about half the fish stocks are said to have been lost in southern Norway, and some 4000 medium to large sized lakes are recorded as being very seriously acidified. Loss of fish has obvious knock-on effects on birds. In the UK there has been more limited acid impoverishment of freshwaters because the areas of vulnerable geology are smaller, but there have been losses of invertebrates, threats to some local races of fish in southern Scotland, and reductions in the populations of some birds like the dipper. We now believe that these changes are not the direct result of acids falling into the rivers and lakes, but are mediated through a complex series of interactions in the soil, with the build up of a sulphur reservoir 
there, and the release following acidification of aluminium, which is directly toxic to fish species, the impact being greatest where the waters in question are also impoverished in calcium. The acidification of many of these waters has probably been building up since the beginning of the industrial revolution (this is clearly indicated by the changing diatom floras in sediment cores from a number of lakes), and it may take decades of reduced emissions plus corrective additions of limestone to swing the ecological systems back towards their earlier condition. Nonetheless this is a phenomenon that, however serious, is substantially confined to acid rocks in parts of Canada, the US, Scandinavia and western and central Europe, just as the dieback of European forests, which reflects a different interplay of climate, air pollution and land use, is restricted in extent even if devasting to the countries experiencing it.

Other effects of pollution are also largely of regional or even local extent. In the seas, it is in the 'hot spots' of shallow confined waters and estuaries that the effluvia of industrial society are most concentrated and ecosystems impoverished. In western Europe, places like the Danish, German and Dutch Waddensea or the confined waters of the Kattegat are the scenes of most conspicuous change. Concentrations of damaging chemicals such as persistent pesticides have also reached their highest levels in ecosystems in parts of the industrialized world. I would challenge the argument that we are in process of risking mass extinctions as a result of these kinds of phenomena, although they provide a warning that is rightly leading to corrective action. This cautious optimism depends, however, on the maintenance of monitoring and chemical screening systems that will detect possible agents of ecological damage and phase them out before irreversible harm is done.

The fact that such protective action is feasible has been demonstrated by the successful recovery of predatory birds in Britain following curbs on persistent organochlorine pesticides and actions to eliminate the use of polychlorinated biphenyls, and more recently by measures to limit the organo-tin compounds whose value in boat antifouling paint is undermined by their severe ecological impact, especially on molluscs.

\section{Man as an agent of biological distribution}

The second major role of humanity in altering the natural world arises from the immense translocation of species caused by people. Much of this has been deliberate. Cattle, sheep, pigs, goats, dogs, cats, rabbits, species of deer, fur-bearing animals like mink, musk-rat and coypu and many other allegedly useful species have been injected into new habitats. Alongside them have come species transported out of some weird nostalgia-like European birds taken to New Zealand and North America (apparently in some cases so that all the species mentioned by Shakespeare could cheer the settlers in their new homes). In turn, such translocations led to pressure on predators and competitors, and the transformation of vegetation-especially plant communities like some on oceanic islands not previously exposed to grazing.

The ecology of invasions, well documented in classic works such as that by Elton (1958), was recently reviewed at a Royal Society discussion, which attempted to define criteria for success (Royal Society, 1987): for this reason no detailed summary will be given here. But what can be said is that, whereas the diversity of the world's flora and fauna is the result, in considerable part, of evolution in isolation, behind the barriers of ocean, mountain or desert, human action in translocating species must progressively create greater biotic uniformity. Pangaea broke up millions of years ago. We are substituting Mangaea (if classical scholars will forgive the appalling barbarity of the term). Even in rich and apparently untouched habitats there are cosmopolitan invertebrates transported by man. For example, 64 out of 199 terrestrial (non-parasitic) invertebrates recorded from the Tristan da Cunha Islands in 1965 were thus imported (Holdgate, 1965). Those who have worked on oceanic islands are well aware of the threat to their unique species that follows alien introduction and habitat disturbance. It is true that much has been done for the protection of such species and habitats, for example via IUCN. But, given the scale of the world tourist industry and the low rate of introductions required to promote greater uniformity on a time scale of milennia, the process of inter- 
change and blending is likely to prove unstoppable. It will make the world a duller place.

There is further, new, development that can be mentioned only briefly here. In recent years the genetic manipulation of organisms has become a reality. Some altered forms are likely to be released - or escape - to the wild. Their ecological impact, and capacity to exchange genetic material with other individuals, can only be a matter of speculation, but this is an issue that will require thorough study and careful control.

\section{The transformation of habitats by human agency}

The third category of human impact is the greatest. As is well known, world population has been mounting rapidly. It passed 4 billion in 1975 and is calculated to pass 6 billion by the end of the present century. Moreover, the demographic pattern is very asymmetrical between developed and developing countries. Much of the developed world is now at or near population stability, and has achieved this level within the productive capacity of relatively fertile temperate lands leaving room for a considerable amount of natural beauty, amenity and wildlife habitat.

In the developing countries, however, human population growth continues to exert massive pressure on vulnerable ecosystems. In some parts of East Africa populations are still growing at over 4 per cent per annum. In Africa as a whole the rate of population growth actually increased during the 1970s whereas on a world scale the rate of growth was declining (Holdgate et al., 1982). In the 1960s Africa was virtually self-sufficient in food. In 1984 some 140 million people out of a total of 531 million were receiving imported food supplements (Brown and Wolf, 1986). The flow of people from land to cities is causing the latter to burgeon at the expense of adjacent tillable areas.

All this adds up to massive pressure on natural ecosystems, especially for cultivation and fuel wood. Some of the cultivation is spilling over into areas that are self-evidently ecologically fragile, even in relatively well-to-do countries like Kenya where settlement is encroaching on the semi-arid lands of the great rift and the dry plains to the west and south of Nairobi. The consequences in terms of desertification and deforestation are well known. Helping the countries concerned to stabilize this kind of impact is the greatest environmental challenge the world community faces - it is also essential if wildlife diversity is to be preserved.

The World Resources Institute addressed some of the problems when it set up the Global Possible Conference in 1984 (Repetto, 1985). This conference produced an analysis that has been transmuted into action plans for various environmental systems. One of the most advanced is that put forward to stabilize the encroachment on tropical forests (World Resources Institute, 1985). This can only be done by drawing off the human pressures, which in turn means improving sustainable agriculture on adjacent more fertile lands, and establishing fuel wood and timber plantations on which people can draw without making inroads into the natural forests. In parallel, there has to be education, training and health care to secure sustainable resource use, to raise standards of living and to promote population stabilization. The bill is likely to be massive: it has been set at 8 billion dollars a year over the next 5 years - with more thereafter. Similar scales of expenditure are needed to curb desertification: the plan adopted in 1977 by the United Nations (and largely ignored) was costed at \$4.5 billion per annum for the remainder of the century, but the gains - and the costs if nothing is done-are greater. At the moment some countries are raising their income at the cost of their capital of natural resources: it looks good in GNP statistics. However, if a 3 per cent rate of economic growth is founded on a 6 per cent irreversible destruction of the national forest resource, with attendant costs in erosion and hydrological variability, the actual result may be a net impoverishment of the economy as a whole.

The discussions of learned societies, or even intergovernmental conferences, cannot do much to deal with these problems. They can recognize the obvious needs and make eloquent pleas for the commitment of more aid and effort-but this has already been done by many conferences and commissions. The defect of many of the discussions of past years has been that they have led to plans without action. They have failed because 
they have not secured the commitment of governments or reached down to the level of real communities interacting with the real earth. In that sense they have not been practical. Many of the world's great environmental problemsmany of the problems of destruction of habitat and wildlife-are the cumulative consequence of the actions of millions of desperate, poor people who are seeking no more than minimal subsistence, minimal shelter and minimal warmth.

One of the most hopeful outcomes of the 1986 conference in Ottawa, which reviewed the World Conservation Strategy, was its recognition of the need to make contact with and provide for people at the local community level - and particularly the rural poor. Speaker after speaker and working group after working group stressed the need to secure the participation of communities as a whole, giving them information and techniques that they could apply in their own environmental circumstances. The conservation of wildlife and natural habitats needs to be provided for in a matrix of activities, which begins by catering for human needs, improving the lot of people who are living at the margins of desperation, and providing the economic growth and wealth creation without which the great problems of the world are unlikely to be solved. Sustainable development is rightly recognized as the essential keynote of today's people, but sustainable development has to be based on an analysis of the needs of those who are seeking to develop under the real ecological circumstances in which they live.

\section{Conclusion}

We live in a world whose habitats have always changed and whose floras and faunas have always responded with extinction, speciation and distribution. But our richest biotas are not in the areas that have experienced rapid change: they have diversified in such ways because of long periods of stability in favourable circumstances.

For this reason, the rapid changes of today, with the emergence and encroachment of one dominant species-our own-poses a very real threat. The direct impacts of people as cultivators and burners of wood, and as translocators of species, are in my view more serious than our 158 likely indirect effects through the perturbation of the biosphere (always assuming that this stops short of the devastation of nuclear war). Nonetheless, human impact on climate and sea level has the potential to bring about considerable ecological change and augment the more direct and obvious pressures.

We face many great and urgent challenges. Something can, however, be done about pollution, and possibly about the greenhouse effect (although the switch from fossil fuels to nuclear power, which many advocate as part of that solution, will not be easily adopted in a world whose nerves have been jarred by Chernobyl).

We can do less about the inadvertent translocation of ecologically damaging speciesalthough we can avoid foolish mistakes, which in the past have included the introduction of grey squirrels and mink to Britain, rabbits to Kerguelen and Australia, and red deer to New Zealand.

Our greatest challenge, however, is to do something to bring about sustainable development to improve the lot of communities and people in the poorer parts the world. Otherwise environmental devastation, disaster and tragedy will expand on a scale that will make the recent Ethiopian famine look trivial. In order to guide such development we need a basis of science. We need much better knowledge of what is happening in the world, and a much better understanding of how the various actions that we take affect the global system. We need this both to predict and to correct.

Nearer home, we need this kind of knowledge to plan the future of industrial and urban societies, so that the living resources on which all depend are cherished. We need it to guide international relationships - whether over acid rain in Europe or in the aid provided to the developing world. The Global Possible Conference stressed that there is still time to achieve a world in which people live in balance with their environment, with room for the richness and beauty of nature. But we do not have more than the minimum of time for such adjustments, and societies like the FFPS, with a strong professional reputation, dedicated to the preservation of the world's fauna and flora for both the benefit and enjoyment of people, have a significant contribution to make.

Oryx Vol 21 No 3, July 1987 


\section{References}

Brown, L. R. and Wolf, E.C. 1986. Reversing Africa's decline. In: State of the World 1986 (Ed. L. R. Brown), pp. 177-194. W. W. Norton, New York.

Clark, W.C. 1982. (Ed.) Carbon Dioxide Review: 1982. Clarendon Press, Oxford.

Dahl, A.L. 1986. Coastal ecosystems and rapid sea-level rise. The Siren (Newsletter of UNEP Regional Seas Programme), 31, 18-22.

Darlington, P.J. 1957. Zoogeography: the Geographical Distribution of Animals. John Wiley \& Sons, New York.

Ehrlich, P.R., Harte, J., Harwell, M.A., Raven, P.H., Sagan, C., Woodwell, G.M. et al. 1983. Long term biological consequences of nuclear war. Science, 222, 4630.

Elton, C.S. 1958. The Ecology of Invasions by Animals and Plants. Methuen, London.

Environmental Protection Agency 1984. Potential Climatic Impact of Increasing Atmospheric $\mathrm{CO}_{2}$, with Emphasis on Water Availability and Hydrology in the United States. EPA, Washington.

Flohn, H. 1978. Comparison of Antarctic and Arctic climate and its relevance to climatic evolution. In: Antarctic Glacial History and World Palaeoenvironments (Ed. E. M. Van Zinderen Bakker), pp. 3-13. A. A. Balkema, Rotterdam.

Holdgate, M.W. 1965. The fauna of the Tristan da Cuha Islands. Phil. Trans. R. Soc. Lond. B, 249, 361 --402.

Holdgate, M.W., Kassas, M. and White, G.F. (Eds) 1982. The World Environment, 1972-1982, A report by UNEP. Tycooly International, Dublin.

Lamb, H.H. 1970. Volcanic dust in the atmosphere, with a chronology and assessment of its meteorological significance. Phil. Trans. R. Soc. Lond. A, 266, 425533.

Lamb, H.H. 1977. Climate, Present and Future. Methuen, London.
McCormick, J. 1985. Acid Earth. An Earthscan Paperback. International Institute for Environment and Development, London.

Pollack, J.B. 1981. Atmospheres of the terrestrial planets. In: The New Solar System (Eds J. K. Beatty, B. O'Leary and A. Chaikin), pp. 57-70. Cambridge University Press, Cambridge.

Postel, S. 1984. Protecting forests. In: State of the World, 1984 (Ed. L. R. Brown), pp. 74-94. W. W. Norton, New York.

Repetto, R. 1985. The Global Possible. Resources, Development, and the New Century. Yale University Press, New Haven

Royal Society 1984. The ecological effects of deposited sulphur and nitrogen compounds. Phil. Trans. R. Soc. Lond. B, 305, 259-577.

Royal Society 1987. Quantitative Aspects of the Ecology of Biological Invasions. Proceedings of a discussion meeting organized by Sir Hans Kornberg FRS and Professor M.H. Williamson. The Royal Society, London.

Shoemaker, E.M. 1981. The collision of solid bodies. In: The New Solar System (Eds J. K. Beatty, B. O'Leary and A. Chaikin), pp. 33-44. Cambridge University Press, Cambridge.

Simpson, G.G. 1953. Evolution and Geography. Eugene, Oregon.

United Nations Environment Programme 1987. Environmental Data Report. UN Environment Programme, Nairobi (in press).

World Resources Institute 1985. Tropical Forests: A Call For Action. World Resources Institute, Washington DC.

World Resources Institute 1986. World Resources, 1986. Basic Books, New York.

Martin W. Holdgate, Chief Scientist, Department of the Environment, 2 Marsham Street, London SW1P 3EB, UK. 